\title{
La mediación intrajudicial familiar como un método para promover la paz judicial*
}

\author{
The family intra-judicial mediation as a method to promote judicial peace \\ La mediação intrajudicial familiar como un método para promover a paz judicial
}

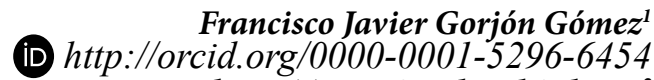 \\ Rubinia Teresa Sandoval Salazar ${ }^{2}$ \\ (iD http://orcid.org/0000-0001-8970-6103 \\ Universidad Autónoma de Nuevo León, México
}

DOI: http://dx.doi.org/10.21803\%2Fpenamer.10.19.471

\begin{abstract}
Resumen
El presente artículo investiga la problemática del sistema judicial en el Estado de Nuevo León, respecto a la derivación judicial en relación a la mediación familiar, ya que a pesar de todo el impulso que el estado ha dado a los Métodos Alternos para la Solución de Conflictos /MASC/, esto no ha sido suficiente para lograr el aumento de la derivación del conflicto familiar dentro de los procesos judiciales familiares, el objetivo de esta investigación es identificar la problemática y proponer una nueva forma para obtener un efectivo acceso a la justicia alterna dentro del sistema judicial, con el fin de lograr que la mediación tenga un rol activo y eficaz dentro del seno judicial, la metodología utilizada es mediante el estudio de la dogmática jurídica referente a la norma jurídica que regula los métodos alternos conjunto con la legislación procesal civil aplicado en el área familiar, analizando en específico la norma que regula la derivación del conflicto dentro de los juicios familiares, como resultado de este estudio se obtiene que si aplicamos la mediación intrajudicial en nuestro ordenamiento jurídico se logrará aumentar las derivaciones de conflictos familiares a la mediación.

Palabras clave: La mediación familiar, La mediación intrajudicial familiar, Convenio de mediación intrajudicial.

\section{Abstract}

The present article reveals the judicial system problem in the state of Nuevo Leon regarding to family issue in relation to a family mediation and despite of all the incentives received from the state in particular to the Alternative Methods for Conflict Resolutions/MASC/ this was not enough to achieve the raising within the familiar judicial processes on this method. The objective of this research is to identify this problem and to improve a new way, which the effective access to this alternative justice inside the legal system plays an effective role. The methodological approach is to review the legal norms refereed to the alternative justice proposed here together with the civil procedural legislation on the familiar area, analyzing the norm that regulates the familiar issue. The conclusion is that by applying this alternative method on family conflict regarding to a legal system, it will raise the mediation regarding to familiar conflict derivations.

Keysword: Family mediation, Family intrajudicial mediation, Intrajudicial mediation agreement.

Resumo

O presente artigo pesquisa a problemática do sistema judicial no estado de Nuevo León, a respeito ao encaminhamento judicial em relação à mediação familiar, já que apesar de todo o impulso que o estado deu aos Métodos Alternativos para a Solução de Conflitos, isso não foi suficiente para conquistar o aumento da derivação do conflito familiar dentro dos processos judiciais familiares. $O$ objetivo dessa pesquisa é identificar o problema e propor uma nova forma para obter acesso efetivo a justiça alternativa dentro do sistema judicial. A metodologia usada parte do estudo da dogmática jurídica referente à norma jurídica que regulamenta os métodos alternativos em conjunto com a legislação processual civil aplicada na área familiar, analisando em específico a norma que regulamenta a derivação do conflito dentro dos juízos familiares. Como resultado deste estudo, conclui-se que se aplicamos a mediação intrajudicial no nosso ordenamento jurídico, conseguiremos aumentar as derivações dos conflitos familiares à mediação.
\end{abstract}

Palavras-chave: Mediação familiar, Mediaçao intrajudicial familiar, Convênio de mediação intrajudicial.

Cómo referenciar este artículo: Gorjón, F. \& Sandoval, R. (2017). La mediación intrajudicial familiar como un método para promover la paz judicial. Pensamiento Americano, 10(19), 175-188. http://dx.doi.org/10.21803\%2Fpenamer.10.19.471

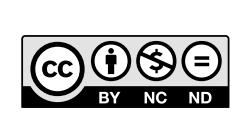

Recibido: Septiembre 24 de 2016 • Aceptado: Enero 15 de 2017

* Mediación intrajudicial en juicios familiares en el estado de Nuevo León.

1. Coordinador del Doctorado en MASC/UANL. fgorjon@hotmail.com

2. Doctoranda en MASC/UANL. ruby_rd@hotmail.com

Pensamiento Americano Vol. 10 - No. 19 • JULio-Diciembre 2017 • Corporación Universitaria Americana • Barranquilla, Colombia • ISSN: 2027-2448 • PP. 175-188 http://coruniamericana.edu.co/publicaciones/oj/index.php/pensamientoamericano 


\section{Introducción}

El sistema judicial de Nuevo León se encuentra saturado por juicios familiares, esto en base de las "estadísticas estatales y nacionales sobre la problemática en los órganos judiciales y ministeriales" (García Herrera, 2006, p.303). Por lo cual se inició la implementación de los métodos alternativos para solucionar los conflictos familiares en nuestro ordenamiento judicial, con el fin de lograr una justicia alterna acorde a las necesidades de las partes inmersas en un conflicto familiar.

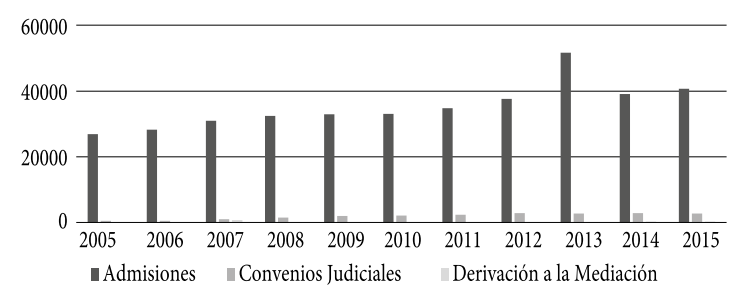

Gráfica 1. Relación de juicios familiares admitidos, los convenios judiciales y los derivados a convenio de mediación

Fuente: Elaboración propia en base de datos del Poder Judicial en el Estado de Nuevo León (2016)

La Gráfica 1 muestra los juicios familiares admitidos, los convenios judiciales celebrados y los derivados por convenios de mediación familiar del periodo 2005 al 2016 en los primeros cuatro distritos en el Estado de Nuevo León.

De la anterior grafica se aprecia que los juicios familiares admitidos anualmente del año 2005 al 2015 ha tenido una alza, y la poca presencia de las derivaciones a la mediación familiar, esto comparado con el número de juicios admitidos, y se refleja una mayor inclinación a los convenios judiciales con respecto a las derivaciones judiciales y en consecuencia se apre- cia la baja presencia de las derivaciones dentro de los procesos judiciales familiares, por ello, la importancia de analizar cuáles son las razones y los obstáculos del sistema judicial que está provocando los bajos desvíos judiciales a la justicia Alterna.

La mediación familiar es una forma de lograr solucionar los conflictos familiares de forma pacífica, pero más que eso, es lograr conservar las relaciones familiares de forma cordial y duradera fomentando el respeto familiar entre las partes afectadas directamente y los afectados de forma indirecta y a su vez dejando atrás las emociones negativas, las desilusiones, los egos, entre muchos más factores que propiciaron desencadenar un juicio familiar.

Las familias por ser la base de la sociedad, se debe buscar la forma de lograr el desvío judicial familiar, para llegar a la mayoría de los núcleos familiares haciendo llegar las bondades de la mediación familiar y despertar valores, habilidades en los núcleos familiares en conflicto, para que propicien el orden, la armonía familiar, y que estos valores familiares sean la base de la sociedad logrando una paz procesal en el orden familiar y a su vez una paz social.

Por tal razón, esta investigación desarrolla un nuevo método de Mediación Intrajudicial Familiar que logre adaptarse a las nuevas necesidades sociales envueltas en conflictos familiares, y permita tener el acceso a la justicia alterna de forma más sencilla y práctica en el Estado y a su vez este método deberá estar re- 
gido por principios procesales que logren su aplicabilidad y operatividad dentro del sistema judicial para lograr la derivación judicial familiar.

\section{Metodología}

La investigación utiliza la dogmática jurídica como metodología. Esta metodología se complementa con el análisis empírico de la realidad que se presenta en los juzgados familiares mediante una entrevista a abogados y jueces familiares y de la evaluación de base de datos publicados e informados por el Poder Judicial en el Estado de Nuevo León. La presente investigación sirve para evaluar la reglamentación jurídica respecto a la mediación, y lograr implementar un método que permita la funcionalidad de la mediación dentro de los juicios familiares orales y tradicionales.

\section{Problemática del proceso judicial familiar}

\section{frente a la mediación familiar}

El Estado de Nuevo León ha trabajado fuertemente para agilizar los procesos judiciales y por tal razón el sistema judicial ha sufrido cambios operativos, reformas procesales con el fin de darle la agilidad procesal, entre ellas la implementación de los juicios orales desde el año 2007, los cuales son regulados por el Código de Procedimientos Civiles en el Estado de Nuevo León, dicho procedimiento oral a permitir la participación activa de los Métodos Alternos para la Solución de Conflictos / MASC/, pero con respecto a los Juicios familiares tradicionales por su forma tradicional y rígida del procedimiento, esto no han ayudado en la participación activa de los MASC.

Tabla 1. Comparativo de las radicaciones, convenios judiciales y las derivaciones a la mediación de los juicios familiares tradicionales $y$ orales

\begin{tabular}{|c|c|c|c|c|c|c|}
\hline Año & $\begin{array}{c}\text { Radicados } \\
\text { Familiares } \\
\text { Tradicionales }\end{array}$ & $\begin{array}{c}\text { Radicados } \\
\text { Familiares Orales }\end{array}$ & $\begin{array}{c}\text { Convenio } \\
\text { judicial familiar } \\
\text { tradicional }\end{array}$ & $\begin{array}{c}\text { Convenio } \\
\text { judicial } \\
\text { familiar oral }\end{array}$ & $\begin{array}{c}\text { Derivación en los } \\
\text { juicios familiares } \\
\text { tradicionales }\end{array}$ & $\begin{array}{c}\text { Derivación en los } \\
\text { juicios familiares } \\
\text { orales }\end{array}$ \\
\hline 2005 & 26829 & 0 & 513 & 0 & 0 & 0 \\
\hline 2006 & 28271 & 0 & 569 & 0 & 0 & 0 \\
\hline 2007 & 22589 & 8306 & 257 & 752 & 17 & 7 \\
\hline 2008 & 22432 & 10022 & 51 & 33 & 43 & 32 \\
\hline 2009 & 22684 & 10212 & 28 & 2025 & 46 & 38 \\
\hline 2010 & 22103 & 10880 & 24 & 2286 & 17 & 37 \\
\hline 2011 & 23831 & 11702 & 33 & 2761 & 44 & 45 \\
\hline 2012 & 24809 & 12825 & 28 & 2753 & 56 & 111 \\
\hline 2013 & 34807 & 16800 & 22 & 2836 & 80 & 128 \\
\hline 2014 & 24328 & 14777 & 19 & 2763 & 71 & 169 \\
\hline 2015 & 26798 & 13906 & 33 & & 38 \\
\hline
\end{tabular}

Fuente: Elaboración propia en base de datos del Poder Judicial en el Estado de Nuevo León (2016) 
La Tabla 1, muestra un cuadro comparativo entre los dos procesos judiciales familiares respecto a la admisión, los convenios judiciales celebrados por la autoridad familiar y las derivaciones a la mediación realizadas por las autoridades familiares.

Dentro de la anterior tabla se observa primero que las admisiones de los juicios familiares tradicionales son mayores comparados con los juicios admitidos por los juzgados familiares orales y que a pesar de ese aumento el número de convenios judiciales celebrados son mayores en los juicios orales que en los juicios tradicionales, lo segundo que se observa respecto a las derivaciones al proceso de mediación, es que en seis años ha sido mayor la presencia de la derivación en los juicios familiares orales, pero sigue siendo baja la presencia de la derivación judicial.

De los anteriores datos arrojados por el Poder Judicial en el Estado de Nuevo León, se desprende que la mediación ha ido en aumento, pero de forma muy paulatina y que dicho aumento sigue siendo bajo comparado con el número de juicios admitidos dentro de los juicios familiares y que las partes prefieren celebrar convenios judiciales que acudir a un proceso de mediación dentro de los juicios familiares. Hierro (2012) afirma que el "proceso evolutivo familiar, es inevitable. En la mayoría de las ocasiones, el Sistema Familiar encuentra una manera adaptativa de enfrentar el cambio" (p.47). La misma sociedad pide cambios en nuestro sistema legal a fin de lograr una justicia alterna al alcance de la sociedad.

\section{La mediación familiar en el Estado de} Nuevo León

La mediación familiar juega un papel relevante dentro de la sociedad y del sistema legal, ya que "el futuro de la humanidad pasa por la familia, son necesarios muchos recursos para preservar y fortalecer esta institución natural, que ahora está en franco peligro pues los ataques a la familia parecería que intentan desajustar tal institución" (Polaino \& Lorente, 2004, p.256). Es necesario buscar la manera de lograr una derivación judicial familiar, con el fin de llegar a acuerdos de mediación familiar.

Pastor e Iglesias (2011) afirman: "La mediación en el ámbito familiar tiene como objeto todos aquellos conflictos que se produzcan en el seno de la familia y supongan una situación de malestar a los miembros de este sistema" (p.77). La mediación familiar pasa de resolver problemas presente a resolver problemas futuros, la cual busca que perdure una relacion social de armonía dentro del nucleo familiar.

Requena (1999) afirma: "la actividad del mediador familiar debe tener siempre en cuenta el interés de los menores, y así el mediador debe ser el garante de tal interés” (p.182). Esto no se debe confundir con "la función de consejero jurídico es la típica de los abogados, y no es propia de los mediadores" (Requena, 1999, p.181). El único que puede asesorar legalmente son los abogados, por el contrario, los mediadores solo pueden informar cuestiones legales derivadas de la mediación. 
Dentro de una mediación familiar debe de tomar en cuenta que "durante el proceso de ruptura de la pareja contiene tanto aspectos emocionales y afectivos, como aspectos legales, todos los cuales deben ser contemplados para una adecuada solución. Estos últimos aspectos, sobre todo en el caso de parejas con hijos" (Montoya Sánchez \& Puerta Lopera, 2012, p.100). Si logramos mantener en control y equilibro las emociones entre las partes y conjuntamente se impulsa el diálogo familiar constructivo y empático entre los miembros de la familia, se podría lograr una solución acorde a las necesidades de su propia familia y buscar una solución en base a las necesidades de cada familia, en particular mediante la mediación.

\section{La mediación en los juicios familiares ora-} les

Dentro del ordenamiento jurídico no existe una ley o reglamento que regule la mediación familiar, en nuestra legislación solo prevé la mediación como MASC de forma general, la cual está contemplada en la Ley de Métodos Alternos para la Solución de Conflictos para el Estado de Nuevo León /LMASCNL/, pero respecto al juicio familiar oral en el Código de Procedimientos Civiles en el Estado de Nuevo León, en su artículo 1052 establece: si asistieren las partes, el juez les propondrá someterse a un método alterno, y si están de acuerdo con esta vía, se procederá conforme a la LMASC$\mathrm{NL}$, no acordando las partes someterse el conflicto a un método alterno, juez procurará la conciliación.
El juez invita a las partes a someterse a un MASC de la siguiente forma: "invita a los contendientes que el presente conflicto, intenten resolverlo a través de un método alterno, informándoseles que existe para ello entre otros, el Centro Estatal de Métodos Alternos para Solución de Conflictos, adscrito a este Tribunal, cuyo domicilio se encuentra en la calle Escobedo número 508 Sur, esquina con calle 15 de Mayo en el Centro de esta ciudad, puntualizándose además de que existe en la actualidad un módulo de dicho centro, ubicado en las instalaciones de este edificio Vali Rent, Séptimo Piso, sito en la calle de Escobedo número 519 Sur Cruz con Allende en el Centro de esta ciudad, lugares donde se ofrecen servicios en forma gratuita a toda aquella persona que necesite ayuda para resolver un conflicto como sería el presente asunto, separándose del procedimiento judicial, para dar oportunidad a dicho método, (...)" (Colunga Molina \& Rodríguez Támez, 2015, p.5).

Esta invitación consiste en suspender la audiencia y acudir al Instituto de Mecanismos Alternativos, para concretar una cita y tratar de llegar a algún convenio a través de la mediación, la invitación de la alternancia, el cual el juez hace una explicación muy breve, la cual no causa interés para lograr que las partes acudan al Instituto, se suspende la audiencia a fin de iniciar el proceso de mediación, ahora bien, en caso de incumplir con el convenio de mediación las partes deberán presentar la ejecución del convenio ante la autoridad judicial en el área familiar, y solicitar la ejecución del con- 
venio de mediación, en caso de que las partes no lograran llegar a un convenio de mediación, deberán solicitar reactivar el juicio, solicitando nueva fecha para la audiencia preliminar a fin de continuar con el juicio.

\section{La mediación en los juicios familiares tra-}

\section{dicionales}

En este proceso no está regulado en qué etapa debe estar presente la invitación a la alternancia y no da margen al diálogo entre las partes y la autoridad judicial, mas sin embargo dentro del Código de Procedimientos Civiles en el Estado de Nuevo León, en su artículo 987 establece: Las controversias susceptibles de transacción o convenio que surjan entre personas capaces, podrán ser sometidas a MASC. La iniciativa para recurrir a los MASC proviene de ambos partes o de una de ellas, antes o durante el procedimiento de arbitraje, por lo que en la práctica se plasma en el acuerdo de admisión; en los últimos párrafos es donde se hace la invitación a la alternancia por parte de la autoridad, pero que no le dan la importancia ni el asesoramiento legal respecto a la invitación a la alternancia.

En caso de que las partes accedan a la invitación a la alternancia, deberán dar aviso al juzgado para suspender el proceso y en caso de llegar a convenio de mediación se debe dar aviso al juzgado, pero en caso de incumplir con el convenio de mediación las partes deberán presentar la ejecución del convenio ante la autoridad judicial, en caso de que las partes no llegaran a un convenio de mediación, de- berán avisar al juzgado que no llegaron a un convenio de mediación y solicitar reactivar el juicio, por lo cual es necesario crear un método que permita despertar el interés de las partes y con ello provocando que los abogados estén en "constante formación; esto es, se actualizan y se capacitan" (Arboleda, Garcés, Murillo \& Pineda, 2017, p.190), respecto a esta etapa de la alternancia y que empiece a lograr la derivación judicial.

Factores que limitan el impulso de los MASC en los juicios familiares

Dentro de los juicios familiares se encuentran regulados dos procesos, uno es oral y el otro tradicional, en el primero solamente se invitan a las partes a participar en los MASC de forma enunciativa por parte del juez, es decir, se hace la invitación a través de una pregunta en el sentido de que si les interesa resolver su conflicto a través de un Método Alterno, omitiendo en esta invitación una información clara y precisa de lo que son los MASC, así como del proceso de mediación, por tal razón el bajo impulso de la derivación judicial.

En los juicios familiares tradicionales la invitación por parte de la autoridad solamente está escrita en un párrafo dentro de la admisión de la demanda, lo cual limita la efectividad de la invitación de la alternancia, la forma de llevarlo a cabo en la práctica no está ayudando a impulsar la derivación judicial dentro de los Juicios.

Pastrana (2009) afirma: "Es entonces atri- 
buible el fracaso, no a la mediación misma, sino a la falta de voluntad de las partes por cooperar en el proceso ganar-ganar" (p.72). La falta de voluntad es causada por la poca información por parte de los abogados hacia sus clientes y la poca persuasión que conlleva dicha invitación por parte de la autoridad judicial, como de los abogados litigantes, impidiendo la efectiva derivación judicial familiar mediante la invitación de la alternancia, dejando por un lado a los MASC.

El capacitado con las habilidades para persuadir, explicar e informar de forma clara $y$ precisa de lo que consiste realmente la invitación de los MASC es el mediador familiar, para que realmente se tenga una verdadera $y$ efectiva invitación hacia la derivación judicial familiar, ya que, "el rol del mediador se revelan como especialmente notable un conjunto de habilidades sociales especialmente vinculadas a lo que significa la resolución constructiva de los conflictos" (Serrano, Lopes, Rodríguez \& Mirón, 2006, p.88). Los mediadores no están teniendo un rol activo dentro de los juicios familiares, el mediador requiere tener nuevas habilidades mediante el diálogo no solo para solucionar conflictos sino también el persuadir a las partes para que voluntariamente accedan a la mediación familiar.

El proceso de mediación tiende a suspender el proceso y deja de ser atractivo para las partes, por lo que, se debe de ver de qué forma puede ser más funcional y a la vez, hacer más efectiva la ejecución del convenio de mediación, por tal razón, se debe empezar a enfocar al estudio de la mediación familiar y lograr la eficacia de esta figura en la mediación en los juicios familiares, y permitir "La provisión de un modelo de solución de conflictos para resolver problemas en el futuro" (Gelbenzu \& Salaberria, 1998, p.85) y que esto se logre de forma inmediata durante los proceso judiciales en el ámbito familiar.

\section{La mediación intrajudicial familiar}

Dentro del sistema judicial se encuentran regulados los MASC, pero el que ha tenido más auge es la figura de la mediación por su flexibilidad y adaptabilidad para lograr desarrollarse en cualquier legislación y por tal razón la mediación "ha ido cobrando una importancia creciente como instrumento complementario de la Administración de Justicia” (Renedo, 2003, p.4), por eso la Mediación Intrajudicial Familiar es la mejor herramienta durante el proceso judicial familiares que permitiría cumplir con el objetivo de impulsar la derivación judicial familiar como una forma de llegar a la justicia alterna de forma efectiva e inmediata.

La mediación en cuanto a su funcionalidad tiende a ser un proceso sencillo y claro y a su vez su flexibilidad permite estar presente en cualquier juicio susceptible de ser mediado desde el más complejo hasta el más simple, por otro lado "Son muy diferentes las posturas sobre la naturaleza de la mediación, sobre si debe ser una alternativa, otro método diferente para resolver conflictos, un mecanismo autónomo de pacificación social, preprocesal, intraprocesal, postprocesal, extrajudicial, o un sistema 
complementario del proceso" (Renedo, 2003, p.5), pero la realidad jurídica de la mediación es que es un procedimiento, que puede especializarse en diferentes áreas.

La mediación tiene un papel integrador, que complementa mediante su fusión con el sistema de justicia familiar, en donde deja de ser una faceta y se llega a un método llamado Mediación Intrajudicial. Pastor e Iglesias (2011) afirman: "La Mediación Intrajudicial es un método alternativo integrado en la Administración de Justicia con el fin de ofrecer una gestión y resolución de conflictos adecuada a los usuarios" (p.85). Es aquí donde la mediación evoluciona y se transforma creando una nueva manera de romper con la barrera de la voluntad y a su vez transformar el conflicto judicial a un convenio de Mediación Intrajudicial Familiar.

\section{Proceso de la mediación intrajudicial fa-} miliar

Lo que se busca dentro del sistema judicial es adquirir métodos que rompan con la apatía social que impida obtener un acceso a la alternancia, donde pueda obtener una solución a su conflicto de forma voluntaria y logrando una sociedad estable en base a los valores culturales, como menciona (Ritzer, 1993, pp.105 y 106). "Los funcionalistas estructurales se han preocupado por la tensión, el cambio y las fuerzas que conducen a la desintegración de la sociedad", es por ello la importancia de crear nuevas formas, métodos y estrategias para permitir la renovación judicial enfocada a la alternancia.
En el método de la Mediación Intrajudicial Familiar interviene el juez, el cual tiene la obligación de mandar a las partes a una sesión informativa que deberá será dirigida por un mediador familiar e intervendrá, en caso de que las partes lleguen a un convenio de mediación, se deberá dar la fuerza ejecutoriada del mismo, y en caso de incumplimiento del convenio de Mediación Intrajudicial se hará de forma directa ante el juez.

El mediador familiar tiene la obligación de estar presente en la sesión informativa, así como las partes, con la finalidad de que el mediador explique de forma detallada, clara y precisa en lo que consiste la Mediación Intrajudicial Familiar, y a su vez persuadiendo, influyendo y motivando a las partes. para que inicien el proceso de mediación en el mismo acto evitando las dilaciones procesales.

Las Partes tienen la obligación y el derecho de acudir a las sesiones informativas de la Mediación Intrajudicial, con el fin de conocer de forma clara y precisa la Mediación Intrajudicial con la intención de despertar el interés para resolver los problemas familiares mediante el proceso de la Mediación Familiar, y los Abogados tienen la obligación y el deber ético de asesor jurídicamente a las partes antes de acudir a la sesión informativa, de lo que consiste y de darle las herramientas jurídicas, para darle la seguridad a las partes de participar en esta sesión informativa y en un momento dado si es deseo de las partes someterse a la Mediación Intrajudicial, saber legalmente dónde están pa- 
rados y cómo deben de conducirse para poder arreglar y hasta dónde pueden ceder y no ceder siempre en base a las necesidades de las partes.

Administración de la Justicia este tiene por función dar la infraestructura judicial para poder dar marcha a la figura de la Mediación Intrajudicial Familiar, desde el capital humano, hasta el estructural y el Instituto de Mecanismos Alternativos para la Solución de Controversias, este tendrá la obligación de proveer de mediadores cuando el juez solicite su apoyo para que se lleve a cabo una sesión informativa.

\section{La sesión informativa y el principio de vo- luntariedad}

La Sesión Informativa tiene como finalidad romper con la barrera de la voluntad, el cual es uno de los principios básicos para iniciar el procedimiento de mediación, esta sesión busca la relación del diálogo que permita el proceso de conocimiento, "en la cual puede cambiar su forma de ver el mundo, de actuar, de pensar y de intervenir" (Gelves, 2010, p.46), y con ello buscar obtener la voluntad de las partes a fin de lograr un convenio de mediación, ya que el éxito de la mediación radica en la participación voluntaria de las partes.

Por lo cual, el método de la Mediación Intrajudicial Familiar busca tener una sesión informativa obligatoria la cual debe estar siempre presidida por un mediador familiar, para poderse llevar acabo es necesario que estén presentes un mediador y las partes, con el fin de informar de manera clara, sencilla y preci- sa, las reglas, los pasos a seguir, las ventajas, y los efectos que tiene un convenio de Mediación Familiar, por lo que el mediador intrajudicial, debe adquirir nuevas herramientas de persuasión, que incentive la motivación de las partes y pueda influir de forma positiva en la voluntad de las partes para participar en el proceso de Mediación Intrajudicial Familiar.

La función de la sesión informativa debe motivar a las partes para participar en el proceso de la Mediación Intrajudicial, ya que "La motivación intrínseca es, por tanto, una poderosa herramienta para superar algunas de las barreras que dificultan la transmisión de conocimiento entre los individuos" (Martín Cruz, Martín Pérez \& Trevilla Cantero, 2009, p.191). Logrando que las partes se interesen por conocer y por otra parte que "los profesionales adquieran destrezas y conocimientos que los califican y los hacen más competitivos en el mercado laboral" (Arboleda et al., 2017, p.190). Incitando a los abogados a aprender un nuevo método dentro del sistema judicial que es la Mediación Intrajudicial y lograr influir en la decisión de las partes en participar en el proceso de Mediación Intrajudicial Familiar, de forma certera, con el objetivo de crear un interés en el proceso de Mediación Intrajudicial.

Esta sesión informativa por ningún motivo violenta el principio de voluntad. Taud (2013) afirma: "El carácter voluntario de la mediación se predica, no tanto respecto de su inicio, sino más bien respecto del mantenimiento en la mediación ya iniciada y de su conclusión me- 
diante un acuerdo" (p.105). La sesión informativa tiene como finalidad romper con la barrera de la voluntad, para incentivar a las partes en litigio a través del diálogo informado acceder a la invitación a la alternancia mediante la Mediación Intrajudicial, y combatiendo el obstáculo del desconocimiento del proceso de la alternancia, y logrando que las partes tengan la libre voluntad de decidir iniciar el proceso de Mediación Intrajudicial, ya que "Si la voluntad carece de libertad, entonces no es voluntad" (Flores, 2013, p.23).

Es también parte de la sesión informativa el "aspecto motivacional de los litigantes, su voluntad de llegar a un buen acuerdo, su confianza en la mediación; en general, su disposición positiva al proceso que están viviendo" (Serrano et al., 2006, p.79), ya que los litigantes deben tener la obligación de asesorar a los clientes y darle las herramientas que requerir dentro del proceso de la Mediación Intrajudicial, también de motivar y darles la confianza legal a las partes, para iniciar con la sesión informativa de un modo accesibles y abiertos ante Mediación Intrajudicial y con más oportunidad de lograr la derivación judicial.

La sesión informativa producirá "conocimiento, lo arrastra a la constante de producción de saber que en el leguaje centra su difusión” (Ferrerira \& Carlos, 2009, p.63), y con ello se logrará la invitación efectiva de la alternancia, ya que, "La voluntad no se mueve a sí misma como causa agente en relación con su primer acto: este ha de venir de fuera" (Gon- zález, 2014, p.98), así que, si las partes en litigio accedan de forma voluntaria, motivadas $y$ convencidas de iniciar la Mediación Intrajudicial, estaríamos iniciando el primer paso para lograr la derivación judicial de forma eficiente.

Convenio de mediación intrajudicial y el

\section{principio de cooperación}

El convenio de Mediación Intrajudicial Familiar, estará regido por el principio de cooperación jurídica, ya que, al momento en que las partes en contienda deciden la derivación judicial y concluyeran con un convenio de mediación, este debe ser en el mismo acto sancionado por el juez que conoce del juicio y darle esa seguridad jurídica eficiente, mediante la intervención del juez elevándolo a categoría de cosa juzgada el convenio de mediación, a lo cual se le denominará convenio de Mediación Intrajudicial Familiar.

Este método trae consigo principios jurídicos los cuales son idóneos para darle la eficacia jurídica. Tinant (2012) afirma: "los llamados principios no siempre son normas. En vez de tener índole imperativa, suelen funcionar como orientaciones" (p.49). Por lo que, si aplicamos de forma correcta estos principios en la Mediación Intrajudicial Familiar, lograríamos la eficacia procesal requerida para lograr el aumento de la derivación judicial.

Los convenios de Mediación Intrajudicial Familiar dan origen a una fusión integradora de cooperación jurídica entre el mediador y el juez, en donde ambos participan de forma ac- 
tiva dentro de este proceso, esto mediante "La cooperación jurídica, (...), mediante la colaboración en la tramitación de los procedimientos, (...), facilitando la práctica de diversas diligencias procesales esenciales para el correcto desenvolvimiento del procedimiento" (Heredia \& Rodríguez, 2013, p.94). Trayendo consigo el derecho a la tutela judicial efectiva, lo cual se logrará al momento en que el juez haga efectivo el convenio de mediación elevándolo a categoría de cosa juzgada de forma efectiva e inmediata.

\section{Ejecución de convenio de mediación intra- judicial}

Cuando el convenio de Mediación Intrajudicial Familiar ha sido incumplido, las partes podrán ejecutar el convenio de forma directa ante el juez sancionador del convenio de Mediación Intrajudicial, "esto implica que necesariamente ha de partirse de un principio cooperativo a la hora de construir el sistema y, también, que este sistema, con las cautelas indispensables, debe fundarse en el principio de mutuo reconocimiento" (Heredia \& Rodríguez, 2013, p.95), esta fusión entre la mediación y la autoridad judicial logra una inmediatez procesal y una eficacia jurídica, que permite dar una seguridad legal.

"Es urgente, pues, mejorar este estado de cosas con el fin de no perder ni una sola oportunidad de progreso e, incluso, de generar otras nuevas gracias a la modernización de nuestro Ordenamiento Jurídico" (Ruiz, 2012, p.8). La Mediación Intrajudicial Familiar busca que las partes en juicio tengan acceso a la justica alterna mediante derivación judicial, otorgándole una seguridad jurídica mediante la integración de procesos de forma eficiente y que permita lograr una voluntad entre las partes en litigio de llegar a un convenio de Mediación Intrajudicial.

\section{Conclusión}

El sistema judicial a pesar de sus reformas y la implementación de nuevos procesos para simplificar los juicios, y evitar las dilaciones procesales, y a su vez lograr que la sociedad empiece a desarrollar nuevas habilidades que permita solucionar sus conflictos familiares a través del diálogo, es por ello que se crearon los MASC en el ordenamiento jurídico, pero esto no ha sido suficiente para lograr, que la sociedad participe en el proceso de mediación.

Dentro de esta investigación queda claro que nuestro sistema judicial requiere de nuevas formas y métodos para llevar el proceso de mediación en relación a los conflictos familiares, a fin de permitir llegar a convenio que permitan a las partes obtener una relación de forma respetuosa, cordial y duradera presente y futura.

La sociedad es cambiante y dinámica, nunca esta estática y conforme pasa el tiempo siempre surgen nuevos conflictos y nuevas formas de aplicar y ver el Derecho, por tal razón es necesario lograr buscar nuevas formas de lograr un efectivo sistema procesal en el área familiar, mediante la aplicación de los principios procesales que permiten la funcionalidad de la 
Mediación dentro de los procesos judiciales en el área familiar.

Este nuevo método de Mediación Intrajudicial y con la aplicación del principio de accesibilidad procesales, a través de la sesión informativa y debidamente regulado por nuestro ordenamiento jurídico, se logrará de forma eficiente la derivación judicial, ya que el sistema judicial sigue estando saturado de juicios familiares susceptibles de mediar, esto por la falta de operatividad y accesibilidad de la mediación dentro de los juicios familiares.

Lo que trata la Mediación Intrajudicial familiar, es primero lograr una obligatoriedad hacia las partes para informarse de forma personal realmente qué es un MASC, de forma directa por el mediador, esta es la persona idónea para informar a las partes de la alternancia, esta misma sesión tiene como segunda función lograr que el mediador influya y logre persuadir a las partes para someterse de forma voluntaria al proceso de mediación, y a su vez motivando a las partes que no habrá dilación procesal, ya que si acceden de forma inmediata al iniciar el proceso judicial a la sesión informativa en este mismo acto se logrará la accesibilidad a la justicia alterna.

Otro de los factores que tendrá como beneficio implementar la sesión informativa es el conocimiento y la difusión del proceso de mediación hacia las partes y con ello motivando y persuadiendo a las partes y dando esa seguridad jurídica hacia las partes, logrando hacer un proceso más eficiente, práctico y sencillo, dando como resultado una paz judicial con una seguridad jurídica.

\section{Referencias bibliográficas}

Arboleda, A.P., Garcés, L.F., Murillo, J.E. \& Pineda, M. (2017). Principios, habilidades y virtudes para el conciliador en Derecho. Revista Pesamiento Americano, 10(18), 190-198. doi:http://dx.doi.org/

Colunga, L. \& Rodríguez, C. (2015). Tribunal Superior de Justicia en el Estado de Nuevo León, 3 de julio de 2015. Recuperado el 2 de septiembre de 2017.

Ferrerira, J. \& Carlos, J. (diciembre de 2009). Elementos de análisis para una relación Derecho-sembiótica y lenguaje. Justicia, 14(16), 62-66. Obtenido de http://revistas.unisimon.edu.co/index.php/justicia/ article/view/628/616

Flores, G. (2013). El concepto de la Libertad Libre en la Introducción a los Principios de la Filosofía del Derecho de G.W.F. Hegel. Pensamiento y Cultura, 16, 18-40. Obtenido de http://web.b. ebscohost.com.remoto.dgb.uanl. $\mathrm{mx} /$ ehost/pdfviewer/pdfviewer?si$\mathrm{d}=83 \mathrm{c} 7 \mathrm{bbcf}-\mathrm{bb} 74-49 \mathrm{eb}-8 \mathrm{c} 91-\mathrm{da}-$ 53d67c0826\%40sessionmgr $107 \& v i-$ $\mathrm{d}=17$ \&hid $=107$

García, C. (2006). Exposición de Motivos de la Reforma Constitucional y Orgánica del Sistema de Justicia Penal del Estado de Nuevo León. Nuevo León, México: Consejo de la Judicatura del Estado de Nuevo León. 
García, L. (2012). Teoría General del Proceso. Estado de México: Red Tercer Milenio S.C.

Gelbenzu, E. \& Salaberria, K. (1998). Intervención en el Proceso de Separación Conyugal: Un caso de Mediación Familiar. Anuario de Psicología Jurídica, 879-100. Obtenido de http:// web.a.ebscohost.com.remoto.dgb.uanl. $\mathrm{mx} /$ ehost/pdfviewer/pdfviewer?si$\mathrm{d}=071 \mathrm{dc} 1 \mathrm{ac}-38 \mathrm{f} 1-4 \mathrm{dd} 0-8 \mathrm{de} 7-0 \mathrm{aa} 3 \mathrm{~b}-$ c031bde\%40session mgr4008\&vi $\mathrm{d}=12$ \&hid $=4106$

Gelves, J.S. (2010). El ser humano, su proyecto de vida vs. Calidad de vida en el trabajo como mediación. Revista Pensamiento Americano, 3(5), 45-49. Obtenido de http://www.coruniamericana.edu. co/publicaciones/ojs/index.php/pensamientoamericano/article/view/45/41

González, C. (2014). ¿Es la voluntad un apetito o un 'Poder'? La perspectiva de Duns Escoto. Anuario Filosófico, 47, 77-102. Obtenido de http://web.a.ebscohost.com.remoto.dgb.uanl.mx/ ehost/pdfviewer/pdfviewer?sid=df2d9c51-735b-4a98-9a89-9cce07ef 336 e $\% 40$ session m gr $4007 \& v$ i $\mathrm{d}=6 \&$ hid $=4214$

Heredia, I. \& Rodríguez, E. (2013). Algunas propuestas para una Futura Ley de Cooperación Jurídica Internacional en Materia Civil. Revista Jurídica de la Univerdidad Autónoma de Madrid, (28), 91-106. Obtenido de http:// web.a.ebscohost.com.remoto.dgb.uanl. $\mathrm{mx} /$ ehost $/$ detail/detail? $\mathrm{vid}=2 \& \mathrm{sid}=-$ 665f0a52-2ae7-4eda-b1fc-24690e43d1f1\%40sessionmgr4006\&hid $=4204 \& b$ data $=$ JkF1dGhUeXBlPWlwL H VybCx 1 a W Q Y 29va211Jmxhbm c 9 ZX M m c 210 Z T 11 a G 9 z d C 1saXZl\#AN=96168343\&db=zbh

Hierro, M. (2012). Funcionalizar el desacuerdo. Definición y propuesta de intervención mediadora ante negociaciones atrasadas. Anuario de Psicología Juridica, 22, 47-54. doi:http://dx.doi.org/10.5093/ aj2012a5

León, P.J. (20 de enero de 2016). Poder Judicial en el Estado de Nuevo León. Obtenido de Poder judicial en el Estado de Nuevo León.

Martín Cruz, N., Martín Perez, V. \& Trevilla Cantero, C. (2009). Influencia de la Motivación Intrínseca y Extrínseca sobre la Transmisión de Conocimiento. El caso de una Organización sin Fines de Lucro. CIRIEC-España, Revista de Economía Pública, Social y Cooperativa, (66), 187211.

Montoya, M.A. \& Puerta, I. (2012). La mediación familiar. El encuentro de las partes como apertura a la tranformación. Opinion Jurídica, 11(22), 97-114. Obtenido de http://web.b.ebscohost.com. remoto.dgb.uanl.mx/ehost/pdfviewer/ pdfviewer?sid=52d09ad1-79a4-46ec-8f 4e-b8545728151f\%40sessionmgr106\&vid $=2$ \&hid $=123$

Pastor, E. \& Iglesias, E. (2011). La Mediación Intrajudicial como Método de resolución de conflictos en el seno familiar. Revista Entramado, 7(1), 72-87. 
Pastrana, L.A. (2009). La mediacion en el Sistema Procesal Acusatorio en México. México D.F.: Flores Editor y Distribuidor S.A. de C.V.

Poder Judicial en el Estado de Nuevo León (2016). Dirección de Planeación y Estadísticas Judicial. Monterrey.

Poder Judicial en el Estado de Nuevo Leon (10 de enero de 2016). Poder Judicial en el Estado de Nuevo León. Obtenido de Poder Judicial en el Estado de Nuevo León: https://www.pjenl.gob.mx/Transparencia/sistema-acceso-informacion.asp

Polaino, A. (2004). Guía para la Mediación Familiar. Persona y Bioética, 18(2), 256-257. Obtenido de http:// web.a.ebscohost.com.remoto.dgb.uanl. $\mathrm{mx} /$ ehost/pdfviewer/pdfviewer?si$\mathrm{d}=071 \mathrm{dc} 1 \mathrm{ac}-38 \mathrm{f} 1-4 \mathrm{dd} 0-8 \mathrm{de} 7-0 \mathrm{aa} 3 \mathrm{~b}-$ c031bde $\% 40$ sessionmgr 4008 \&vi $\mathrm{d}=15$ \&hid $=4106$

Renedo, M.J. (2003). Evitación del Proceso y mediación intrajudicial en la jurisdiccion social. Revista Juridica de Castilla y León, (29), 24.

Requena, M. (1999). La Mediación Familiar en el Ámbito del Consejo de Europa. Anuario de Psicología Jurídica, (9), 1731897. Obtenido de http://web.a.ebscohost.com.remoto.dgb.uanl.mx/ ehost/pdfviewer/pdfviewer?sid=071dc1ac-38f1-4dd0-8de7-0aa3bc031bde$\% 40$ sessionmgr4008\&vid $=5 \&$ hid $=4106$
Ritzer, G. (1993). Teoría Sociológica Contemporánea. México: McGraw-Hill.

Ruiz, A. (2012). Un nuevo entorno jurídico para el crecimiento económico. Actualización Jurídica, (33), 7-18.

Serrano, G., Lopes, C., Rodríguez, D. \& Mirón, L. (2006). Características de los Mediadores y Éxito de la Mediación. Anuario de Psicología Jurídica, 16, 75-88. Obtenido de http://web.a.ebscohost.com.remoto.dgb.uanl.mx/ehost/pdfviewer/pdfviewer?sid=822966d3-7978-43ef-91c0b08e40c0c91c\%40sessionmgr4006\&vi$\mathrm{d}=7$ \&hid $=4204$

Taud, A. (2013). El Principio de Voluntariedad en la Legislación de Mediación Familiar, en Chile. Opinión Jurídica, 12(23), 115-132. Obtenido de http://web.a.ebscohost.com.remoto.dgb.uanl.mx/ehost/ pdfviewer/pdfviewer?sid=ed761999-aeca-415f-8d46-5e5d76da485d\%40sessionmgr4006\&vid $=4 \&$ hid $=4106$

Tinant, E.L. (2012). Principios Jurídicos y Principios Bioéticos. Separación, vinculación, integración. Revista de la Facultad de Derecho, 69, 45-63. 